\title{
Resabios de otros tiempos. Dominio incaico en los valles orientales del norte de Salta, Argentina
}

Relents d'autres temps. Domination inca dans les vallées orientales du nord de Salta, Argentine

Remnants of the past: Inca rule in the eastern valleys of northern Salta, Argentina

Beatriz N. Ventura y Lía Guillermina Oliveto

\section{(Q) OpenEdition}

\section{Journals}

Edición electrónica

URL: http://journals.openedition.org/bifea/5248

DOI: $10.4000 /$ bifea.5248

ISSN: 2076-5827

\section{Editor}

Institut Français d'Études Andines

\section{Edición impresa}

Fecha de publicación: 1 agosto 2014

Paginación: 285-310

ISSN: 0303-7495

\section{Referencia electrónica}

Beatriz N. Ventura y Lía Guillermina Oliveto, «Resabios de otros tiempos. Dominio incaico en los valles orientales del norte de Salta, Argentina », Bulletin de l'Institut français d'études andines [En línea], 43 (2) | 2014, Publicado el 08 agosto 2014, consultado el 10 diciembre 2020. URL : http:// journals.openedition.org/bifea/5248; DOI : https://doi.org/10.4000/bifea.5248

\section{(c) $(1) \odot$}

Les contenus du Bulletin de l'Institut français d'études andines sont mis à disposition selon les termes de la licence Creative Commons Attribution - Pas d'Utilisation Commerciale - Pas de Modification 4.0 International. 


\title{
Resabios de otros tiempos. Dominio incaico en los valles orientales del norte de Salta, Argentina
}

\author{
Beatriz N. Ventura* \\ Lía Guillermina Oliveto**
}

\section{Resumen}

Este artículo analiza las modalidades de la ocupación inca en los valles orientales del norte de la actual Salta (Argentina). El estudio se basa en la revisión de investigaciones previas y en el análisis de documentación y cartografía colonial y del registro arqueológico regional. La confrontación de los datos sugiere que la administración inca de esta región de la frontera suroriental del Tawantinsuyu dio lugar al desarrollo de dos territorios bien diferenciados en términos socioeconómicos. Bajo el dominio inca, la región experimentó una intensa dinámica poblacional caracterizada por la instalación de mitmaqkuna para la explotación minero metalúrgica y agrícola y por los movimientos de pueblos provenientes del oriente.

Palabras clave: valles orientales de Salta, territorio, Tawantinsuyu, Inca

\section{Relents d'autres temps. Domination inca dans les vallées orientales du nord de Salta, Argentine}

\section{Résumé}

Cet article analyse les modalités de l'occupation inca dans les vallées orientales du nord de l'actuelle province de Salta (Argentine). Cette étude se base sur la révision des travaux de recherche préalables

* CONICET/UBA, Instituto de Arqueología, Facultad de Filosofía y Letras, Universidad de Buenos Aires, Argentina. E-mail: beatrizventura2006@yahoo.com.ar

${ }^{* *}$ Consejo Nacional de Investigaciones Científicas y Técnicas, Programa de Historia de América Latina, Instituto de Historia Argentina y Americana, Facultad de Filosofía y Letras, Universidad de Buenos Aires. E-mail: guilleoliveto@yahoo.com 
et l'analyse des documents, de la cartographie coloniale, ainsi que du registre archéologique régional. La confrontation des données suggère que l'administration inca de cette région de la frontière sudorientale du Tawantinsuyu a donné lieu au développement de deux espaces bien différenciées du point de vue socio-économique. Sous la domination inca, la région a connu une intense dynamique de populations, caractérisée par l'installation de mitmaqkuna pour l'exploitation minéro-métallurgique et agricole, ainsi que par les mouvements de populations en provenance de l'orient.

Mots-clés : vallées orientales de Salta, territoire, Tawantinsuyu, Inca

\title{
Remnants of the past: Inca rule in the eastern valleys of northern Salta, Argentina
}

\begin{abstract}
This paper analyzes the modalities of the Inca occupation in the eastern valleys of the northern part of the present day Salta (Argentina). This study is based on an examination of previous research and the study of documents and colonial cartography and the regional archaeological record. The comparison of the data suggests that the Inca administration in this region of the south-eastern border of the Tawantinsuyu allowed the development of two territories that were very well differentiated in socioeconomic terms. Under the Inca domination, the region experienced an intense population dynamic, characterized by the introduction of the mitmaqkuna tied to mineral-metallurgical and agricultural extraction, and by population movements of groups coming from the east.
\end{abstract}

Keywords: eastern valleys of Salta, territory, Tawantinsuyu, Inca

\section{INTRODUCCIÓN}

El Tawantinsuyu comprendió un territorio extenso y diverso, producto de la conquista de numerosas poblaciones y geografías a fin de sostener los requerimientos de un sistema en rápida expansión. Para satisfacer la demanda constante de mano de obra necesaria para la explotación de los recursos de las tierras conquistadas, los incas diseñaron una compleja organización socioeconómica que tuvo características específicas en cada región de acuerdo con las estructuras preincaicas existentes y la respuesta de las poblaciones conquistadas. La riqueza de recursos de las selvas, bosques y pastizales que se extienden en la dilatada frontera al este de la Cordillera Oriental atrajo al poder centralizado del Cusco. Así se estructuraron en los valles orientales de los actuales Perú, Bolivia y Argentina espacios diferenciados de acuerdo con los objetivos de la dominación, implementando, en ciertos casos, el traslado de poblaciones en calidad de mitmaqkuna que cumplieron funciones económicas, sociopolíticas y de defensa (Renard Casevitz et al., 1988; Alconini, 2004). En investigaciones anteriores registramos esta dinámica poblacional en los valles orientales de Tarija (Bolivia) y norte de Salta (Argentina), frontera de disputa e interacción entre poblaciones de diversos orígenes (Oliveto \& Ventura, 2009).

En este artículo analizamos la ocupación incaica en las Yungas del norte de Salta (Argentina), uno de los sectores menos estudiados de la frontera oriental incaica. A partir del estudio exhaustivo de investigaciones previas, documentación y 
cartografía colonial y del registro arqueológico, distinguimos la estructuración de dos espacios diferenciados en función de los objetivos cusqueños.

El área analizada corresponde a los valles ubicados al oriente de las Serranías de Zenta y Santa Victoria (Cordillera Oriental), dentro de la Provincia Fitogeográfica de las Yungas (Cabrera, 1976), (fig. 1). El relieve de estos valles se caracteriza por el alto cordón montañoso de la Cordillera Oriental, y se complejiza por las sierras subandinas que, con alturas menores, ocupan una posición intermedia entre esa cordillera y la llanura chaqueña al este. Los diversos ambientes que presenta esta región abarcan los pastizales de neblina, los bosques montanos y las selvas montana y pedemontana.

En época colonial estos valles formaron parte de lo que paulatinamente se fue conociendo como «el Chaco» refiriendo, según el jesuita Pedro Lozano (1941 [1733]: 18, 2 y 20), a las diversas «naciones infieles» que ocupaban las serranías orientales, así como los llanos contiguos. Su crónica es una fuente que, no obstante ser del siglo XVIII, aporta valiosa información, ya que recupera documentos anteriores al citar directa o indirectamente las Cartas Anuas que los jesuitas habían acumulado durante décadas y también documentos elaborados por otros españoles que actuaron en la región desde el final del siglo XVI. Lozano, además de haber accedido a estas fuentes, recorrió el territorio del Chaco lo cual, sin dudas, amplió su capacidad de interpretación de estos escritos.

Los valles que analizamos fueron de tardía colonización y, a principios del siglo XVIII, los españoles tenían escaso conocimiento de ese territorio que aún no ocupaban pero que ansiaban dominar y reducir a sus poblaciones. Con lo cual, para nuestra zona de estudio, Lozano merece ser considerado críticamente como una fuente secundaria que brinda información temprana y, con los recaudos del caso, aporta información útil en la ubicación de las poblaciones que ocuparon el Chaco en el siglo XVII.

El Chaco, comprendía tanto las serranías orientales como la selva pedemontana y el bosque chaqueño aledaño. Posteriormente estas tres zonas serán conceptualizadas por separado y solo los llanos de este bosque se considerarán como territorio chaqueño. Las serranías, actualmente denominadas de Zenta y Santa Victoria, (fig. 1) se mencionan en la documentación como «Cordillera que separa el Chaco del Perú» (Mapa de la Biblioteca Nacional de Francia, París [BNF]) o «serranías que dividen al Chaco del Perú» (Lozano, 1941 [1733]: 50), como el límite entre dos espacios naturales y sociales diferentes en lo que actualmente es Bolivia y el norte argentino. A estas estribaciones también se las llamaba «Cordillera de los ocloyas» en el sector de las Serranías de Zenta, mientras que las Serranías de Santa Victoria fueron denominadas como «Cordillera de los Chichas» o «de Cozquina» (Ledesma de Valderrama in Pastells, 1912: 94; Doucet, 1993: 45; Torre Revello, 1943: 100; Furlong Cardiff, 1936: Lámina XLVIII; Russo de Borelli, 2007:165).

En resumen, a través de distintos registros —la documentación histórica y cartográfica y la evidencia arqueológica - analizamos este sector de la frontera oriental, caracterizado por un gran dinamismo poblacional bajo el dominio del Tawantinsuyu. Los movimientos de distintas poblaciones se incrementaron con la 
desarticulación del poder central mientras no se había consolidado aún el sistema colonial. Paralelamente, grupos del Chaco oriental comenzaron a incursionar en los territorios sometidos por los incas estimulando mayor movilidad de poblaciones en el área. Resabios de esta intensa dinámica quedaron en los registros como un momento de transición que ofrece una notable riqueza, ya que nos permite indagar en la estructuración del área por parte de los incas. Además, nos acerca a las estrategias implementadas por las poblaciones indígenas para escapar de la presión que le imponían sus vecinos orientales y también la dominación colonial, que trataba de «robarles la joya más preciada de la libertad» (Lozano, 1941: 18).

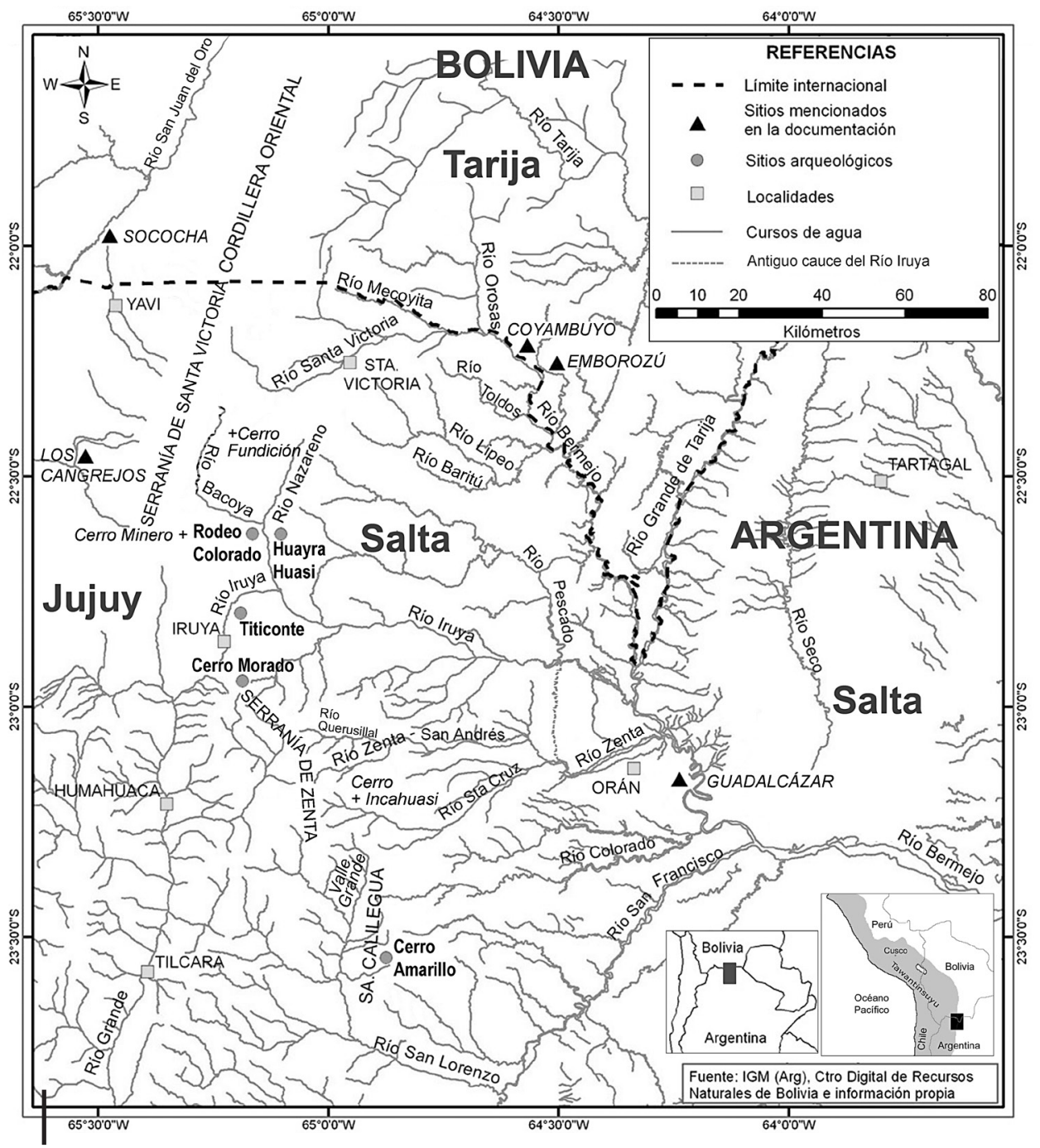

Figura 1- Mapa general del área de estudio 


\section{METODOLOGÍA Y ANTECEDENTES}

Como explicitamos, hemos relacionado documentación colonial y el registro arqueológico regional, integrando críticamente la información que presenta la cartografía histórica para identificar el estado del poblamiento multiétnico de la región durante la época inca.

En relación a la cartografía, conviene señalar que las percepciones del espacio, las convenciones geográficas así como los sistemas de orientación espaciales de los siglos XVII y XVIII no son los mismos que los actuales (Sica, 2003: 17). Aunque el acercamiento que realizamos a la cartografía histórica es exploratorio y preliminar, nuestro conocimiento del espacio geográfico nos habilita a realizar interpretaciones sobre este tipo de registros, debidamente contextualizados con la documentación histórica. En el análisis de los mapas nos limitamos al territorio que actualmente corresponde a los valles orientales salteños. Por el momento, implica la localización de ciertas poblaciones y topónimos mencionados en la documentación en función del conocimiento que el dominio colonial tenía en este momento temprano sobre los grupos ubicados al este de la Cordillera Oriental, entendiendo que la confección de mapas formó parte de la concreción de ese dominio (Penhos, 2005).

Tanto el registro arqueológico como el histórico brindan indicios de situaciones complejas que apenas alcanzamos a dilucidar, más aún debido a lo limitado de los datos arqueológicos con los que contamos para los tiempos preincaicos. La documentación colonial refiere a grupos indígenas singularizados («los ocloyas», los «churumatas», «los paypayas», etc.), sin embargo, bajo esas denominaciones puede ocultarse una heterogeneidad que no vislumbramos, o se está fragmentando una realidad en la que existían vínculos que se nos escapan.

En el estado actual de las investigaciones, no asociaremos el registro arqueológico directamente con los etnónimos registrados en la cartografía y en la documentación. No existen, por el momento, indicadores fehacientes que fundamente el otorgarle a los sitios y a sus materiales una etnicidad determinada. No obstante, en el registro se presentan indicadores que nos permiten asociarlo con poblaciones diferenciadas en cuanto a su posición social y función, más allá de su etnicidad.

Delimitar, nombrar y localizar en mapas a la población indígena precolombina supone dificultades a veces insalvables, ya que los españoles llevaron adelante ciertos procedimientos heurísticos que opacan el entendimiento al establecer etnónimos que podrían ser nombres genéricos o categoriales, extensión del nombre de autoridades o de los topónimos donde fueron localizados.

Consideramos cinco mapas del siglo XVII, elaborados con diversos objetivos y escalas, donde nuestra área de estudio se representa con algún grado de detalle. Los más tempranos $(1609,1632$ y 1647) corresponden a cartografía jesuítica (Torres, 1927 [1609]: Lámina I; Furlong, 1936: Láminas II y III). Contamos también con un mapa de fecha estimada en la primera mitad del siglo XVII, confeccionado con objetivos mineros, aunque aporta valiosos datos sobre otros temas (BNF). Por 
último, un mapa de 1683 realizado por un cosmógrafo real que da cuenta del dominio político entre el sur de Cochabamba y el Río de la Plata (AGI, 1683).

Las fuentes documentales disponibles sobre los valles orientales de Salta durante los siglos XVI y XVII son escasas y dispersas. Esto se debe a la fecha tardía de su colonización y la consiguiente inexistencia de una ciudad española que pudiera constituirse en la sede de actos notariales y oficiales que quedaran registrados. Las fuentes del siglo XVI son más que exiguas, se limitan a una descripción geográfica, una escueta referencia en una encomienda otorgada por Pizarro cuando ningún español conocía los valles y una presentación judicial en la recientemente fundada Jujuy. Este poblado, creado definitivamente en 1593 en los valles orientales al sur de nuestro espacio de estudio, provee documentación que también consideramos. Los escritos de los sacerdotes que transitaron el noreste salteño desde los albores del siglo XVII, a los que accedemos a través de Lozano, adquieren gran relevancia frente al panorama planteado, lo mismo que las cartas del fundador de la frustrada ciudad de Santiago de Guadalcázar en las Yungas salteñas.

En cuanto al registro arqueológico, hemos utilizado información proveniente de investigaciones previas llevadas a cabo en estos valles orientales por Eduardo Casanova (1930), Salvador Debenedetti (Debenedetti \& Casanova, 1933-1935) y Fernando Márquez Miranda en la década de 1930 (Márquez Miranda, 1937; 1939). Los materiales recuperados en estas expediciones nunca fueron estudiados sistemáticamente, por lo tanto, incluimos el análisis de estas colecciones, principalmente la Colección Márquez Miranda que cuenta con más de 1000 piezas y se halla depositada en el Museo de Ciencias Naturales de la Plata (MCNLP). Las informaciones de las prospecciones de José Togo (1973) en Santa Victoria y de Rodolfo Raffino y colaboradores (1986) en un sector del valle de Iruya se sumaron a nuestros propios trabajos de campo en la región (Ventura, 1999; 2001; 2007; 2013). Intentamos integrar ese cúmulo de información al registro arqueológico regional que se extiende desde el valle de Zenta-San Andrés, al sur, hasta el río Bermejo en la frontera con Bolivia, al norte.

En este análisis debemos destacar algunas limitaciones debidas a las diferencias en las muestras tratadas y en los objetivos y metodologías que generaron el registro arqueológico estudiado. Claramente, la muestra proveniente de las excavaciones en los valles de Iruya, Bacoya y Nazareno es mayor y proviene de contextos funerarios, objetivo principal en las expediciones de los años 1930. La falta de dataciones radiocarbónicas es otro limitante, por lo que, aquí nos referiremos a los sitios que presentan rasgos constructivos y/o materiales arqueológicos, tanto en superficie como proveniente de excavaciones, asignados a momentos incaicos. El estudio sobre la ocupación incaica de espacios fronterizos y de las dinámicas poblacionales asociadas, tal como aquí proponemos, privilegia un enfoque integrador de distintos registros en una zona hasta ahora poco investigada. La profundización de estos análisis aportará al conocimiento sobre las complejas estrategias de reestructuración que el Tawantinsuyu impulsó en el extremo suroriental de sus dominios. 


\section{HUELLAS DOCUMENTALES DE LA PRESENCIA INCAICA: POBLACIONES Y EXPLOTACIÓN ECONÓMICA}

A continuación identificamos las distintas poblaciones que ocuparon estos valles del norte de Salta durante la dominación incaica según la documentación histórica, señalando, además, las actividades que habrían desarrollado. Estudios previos propusieron que los incas establecieron allí un enclave multiétnico. Esa colonia incaica se asentaba en un espacio al que las fuentes coloniales llamaron el «valle de ocloyas». Así se designa, en realidad, a varios valles con una ubicación poco precisa al noreste de Humahuaca y al oriente de la Serranía de Zenta. El «valle de ocloyas» tendría para el padre Gabriel Tommasini (1990 [1933]: 39) una extensión de unas 20 a 25 leguas, en sentido norte-sur, conteniendo diferentes poblaciones y pueblos con sus respectivas autoridades. Posteriormente, otros autores (Salas, 1945; González, 1982; Lorandi, 1984; Sánchez \& Sica, 1990) lo localizan en el actual valle de Zenta-San Andrés y otros ríos de esa cuenca, en el norte salteño, mientras que Anahí lácona y Rodolfo Raffino (1993) lo identifican con el valle de Iruya y, Gastón Doucet (1993) y Juan Pablo Ferreiro (1994) lo ubican más al sur, en el actual oriente jujeño. En nuestro caso, consideramos que el «valle de ocloyas» comprendía, además del Zenta-San Andrés, a los distintos valles que se extienden desde Valle Grande en Jujuy, al sur, hasta el de Iruya, al norte (fig. 1).

Este «valle» tuvo, como otros de la frontera oriental del Tawantinsuyu, una configuración multiétnica. Ocloyas, churumatas, paypayas, ossas, gaypetes y chuis fueron las poblaciones relocalizadas por los incas como mitmaqkuna.

Ana María Lorandi (1984) es la primera en proponer que en el «valle de ocloyas» se estableció un enclave productivo de los indígenas de Omaguaca, quienes estaban sometidos a los incas. Sin embargo, no puede asegurar si se trató de un enclave étnico preincaico de Omaguaca o si fue estructurado por los incas. Profundizando esos estudios, Sandra Sánchez y Gabriela Sica (1990) proponen que en el valle de Zenta se desarrollarían la agricultura, la minería y la explotación de los recursos de los bosques y selvas, considerándolo, además, como un enclave defensivo. Postulan que, a partir de la reestructuración del Tawantinsuyu, los ocloyas concentraron los vínculos e intercambios con pueblos más orientales accediendo a los recursos de bosques, selvas y ríos.

La primera mención a «ocloyas» es de 1582 por el capitán Pedro Sotelo de Narváez quien da una ubicación poco clara de este territorio localizado entre el valle de Jujuy (a diez leguas) y el río Bermejo:

los indios están en una tierra fragosa que llaman ocloya, tierra de mucho oro, a las vertientes de la cual está la gente que hemos dicho del río Bermejo. Está esta gente de ocloya como a diez leguas del valle, es gente del Pirú; confinan con otra gente que llaman los Tobas, gente bilicosa, más alta y desproporcionada, los cuales los van apocando y robando cada día (Sotelo de Narváez 1965 [1582]: 150-151).

Interesa destacar, por un lado, la definición de los indígenas que habitaban un territorio rico en metales (oro), como «gente del Perú» ocupando un espacio 
identificado con el topónimo ocloya (término que no se presenta como etnónimo). En este tipo de fuentes, la «tierra» puede referir también a los pobladores de ese territorio. En el mismo sentido, lo «fragoso» indica un espacio con grandes desniveles pero también a una topografía cargada de significados sociales, como un territorio asocial, en guerra, fuera de los límites conocidos por los españoles (Martínez, 1995: 261). Por otro lado, la referencia a la cercanía y conflictividad con los tobas trasunta un escenario de hostilidad que podría ser causado por la intromisión por parte del Tawantinsuyu de grupos ajenos a esos valles orientales, antes aprovechados por las poblaciones chaqueñas y ahora disputados por las andinas.

En cuanto a los grupos que ocuparon el «valle de ocloyas», la cita más utilizada para referirse a las características de los ocloyas es la descripción del jesuita Diego de Torres en las Cartas Anuas de 1609 (Torres, 1927: 35). Allí refiere a una entrada realizada unos tres años antes por un capitán anónimo desde Salta hacia una dirección que no se explicita. En ella, supo de la existencia de miles de indígenas de diversos grupos con costumbres y organización social diferenciada, como los matagua y, tres jornadas «más adelante» (sin dar una referencia geográfica) ubica a los frentones y a los chiriguanos. Luego dice:

Aquí [¿dónde?] tuvieron noticia de que diez jornadas adelante [¿en qué dirección?] hay una provincia de mucha gente labradora que anda vestida tienen muchos pueblos de casas redondas y calles bien ordenadas y que no tienen ríos sino pozos y dicen que es dificultosa la entrada por la falta de agua sino se hace cuando llueve, dicen que en toda esta tierra hace mucho calor que las noches son muy apacibles y que son de temple sanos - de Omaguaca Pueblo de indios veinticinco leguas más adelante de Salta el postigo de esta gobernación hacia el Perú se entra a los ocloyas que están ocho leguas de allí y de buen camino las tres que las demás son asperísimas estas serán no más que dos mil personas han salido los caciques algunas veces a pedir sacerdotes que les hagas cristianos dicen que no dista de ellos la gran provincia del Chaco (veinte leguas) (Torres, 1927: 35).

Esta cita, utilizada por Lorandi (1984: 124) e incluso por nosotras como una referencia a los ocloyas (Oliveto \& Ventura, 2009), podría no ser un testimonio inequívoco sobre ese grupo. Además de que esta mención es de segunda mano y muy imprecisa, su interpretación se ve opacada por la escritura de la época. A principios del siglo XVII los escritos aún presentaban uniones y separaciones arbitrarias entre palabras, sin establecer signos de puntuación o utilizando algunos de forma no convencional como, en este caso, el guión. Nos preguntamos si el párrafo citado describe en su extensión a los ocloyas o a dos espacios y poblaciones diferentes, separadas a partir del guión.

De esta cita resaltamos la dificultad de acceso a la zona de los ocloyas, ubicados a 8 leguas del pueblo de Humahuaca. Lo mismo se destaca, en la crónica de 1683 del padre Diego Ruiz que relata el viaje de Humahuaca hacia el Chaco (Lozano, 1941: 235). Consultado un mapa actual o realizando el trayecto (Ventura et al., 1991), veremos que las primeras leguas, hasta Sianzo aproximadamente, son efectivamente de buen camino, pasados los $3500 \mathrm{msnm}$ se hace dificultoso y, 
el cruce del Zenta al igual que la bajada, merecen el calificativo de «asperísimos», debido a lo escarpado del terreno, los fuertes vientos, los precipicios y las abruptas pendientes.

Las funciones que los ocloyas cumplieron estarían relacionadas con su sujeción incaica a los omaguacas de la quebrada, aún cuando no conozcamos sus implicancias. Aparentemente, parte de los ocloyas estaban sujetos al cacique del valle de Omahuaca desde «el tiempo del ynga» (A.T.J., 1596: f.10v). Este vínculo de subordinación política de los ocloyas podría formar parte de las transformaciones que impuso el dominio incaico. Los omaguacas tenían su siembra antelada de maíz en el valle de Zenta y, probablemente, fueran los ocloyas los que realizaran esa tarea como mitmaqkuna (Sánchez \& Sica, 1990).

Un expediente judicial de 1612 copia la encomienda otorgada a Juan Ochoa de Zárate en 1601 consultada por Salas (1945: 56) y Sánchez \& Sica (1990: 475) e informa sobre los asentamientos ocloyas en Zenta. En esa fecha ya se habían entregado ciertos grupos en encomienda y producido desde 1595 traslados forzados de esta población hacia los valles del oriente jujeño. No obstante, este documento podría evidenciar ciertas características de la configuración poblacional prehispánica del «valle de ocloyas». En el cuadro 1 señalamos los nombres de los pueblos ocloya y sus caciques¹.

Cuadro 1 - Poblaciones y caciques que ocupaban el «valle de ocloyas» en 1601

\begin{tabular}{|l|l|}
\hline Pueblos en el valle y provincia de Ocloya 1601 & \multicolumn{1}{c|}{ Caciques } \\
\hline Chicza & - \\
\hline Sicaya & - \\
\hline Acalayso - Ticalayso* & Cattat Tolaue \\
\hline Toctoca & Cattar Tolaue - Catatte Tolave* \\
\hline Quispira & Caqui Lamas \\
\hline Ocayacxu & Lamas Caque \\
\hline Estoybalo & Jarabor - Jambor* \\
\hline Panaya & Tinti Lamas \\
\hline Sopra -Sopras* & Guarconte \\
\hline
\end{tabular}

*Transcripción de Sánchez y Sica (1990), difiere con la de Salas (1945)

Algunos de esos poblados ocloya aparecen mencionados en la cartografía jesuítica de la primera mitad del siglo XVII que acompañaron a las Cartas Anuas y su información fue incorporada en las investigaciones etnohistóricas de la región (Salas, 1945; Sánchez \& Sica, 1990; Ferreiro, 1994, entre otros).

1 A pesar de la dificultad de establecer sólidas relaciones entre nombres propios de individuos y pertenencias étnicas, el análisis de los nombres y apellidos aporta pistas en las investigaciones. Esto excede el marco de nuestro trabajo, pero queremos señalar que Tolava/Tolave es considerado por Presta \& del Río (1995: 229) como ligado al mundo churumata mientras que Palomeque (2010) lo identifica como apellido chicha. 
El mapa más antiguo que se conoce de la provincia jesuítica del Paraguay (jurisdicción a la que pertenecía el norte de Salta) es el que elaboró en 1609 Diego de Torres (1927: Lámina I) y podría presentar una imagen cercana a momentos prehispánicos de los valles orientales. De esta carta geográfica se conocen dos versiones del siglo XVII, aunque no presentan discrepancias en nuestro espacio ya que provienen de una misma matriz; por eso consideramos la información registrada en la primera2 ${ }^{2}$. En ella encontramos a los «Occloias» y «Guispiras», ubicados al este de un río sin nombre, al oeste del Pilcomayo. Al sur de estas poblaciones, se registran los poblados «Tacalayso» al este del Bermejo y «Chicza» y «Sicaya». Identificado el primero como reducción de indios cristianizados y los otros como poblados de indios infieles. Localizados más al oeste, junto a un afluente del Bermejo, en unas serranías sin identificación, están los «Guarcontes» y «Orechones» a los que se sindica como indios infieles ${ }^{3}$. Interesa remarcar que en la encomienda de ocloyas de 1601, Guarconte es el nombre del cacique del pueblo ocloya de Sopra.

El «valle de ocloyas» también estuvo habitado por los churumatas (Salas, 1945; Sánchez \& Sica, 1990). Este grupo, de gran dispersión en los valles orientales bolivianos (desde Cochabamba a Tarija), habría cumplido funciones productivas y defensivas de acuerdo con las disposiciones incaicas. El empuje de los chiriguanos produjo movimientos de estos pueblos a lo largo de la frontera oriental 4 .

Muchos churumatas que se localizaban en el valle de Zenta, al igual que los ocloyas, fueron tempranamente encomendados (1582) y retirados de ese valle (Sánchez \& Sica, 1990), sin embargo, siguieron manteniendo allí algunas de sus poblaciones. Posiblemente, estos movimientos y la ubicación de otros grupos de churumatas en sectores más septentrionales de la frontera, entre el valle de Zenta y el sur de Tarija, generó confusiones entre los investigadores (Jolis, 1972 en Ferreiro, 1994: 8).

Junto a los churumatas, se identifica a los chuis, ubicados en cuatro pueblos cuyos nombres no figuran en las fuentes. Estos chuis, reputados como «indios de arco y flecha» cumplirían funciones militares al igual que en su lugar de procedencia en Cochabamba (Sánchez \& Sica, 1990).

Tanto osas (de debatido origen) como paypayas (provenientes del sur de Chuquisaca) desarrollarían actividades agrícolas y ganaderas para el Tawantinsuyu. Por último, los gaypetes (identificados como fracción de los osas o paypayas) estarían especializados en trabajos mineros (Sánchez, 2003).

La documentación (Valderrama en Pastells, 1912; Lozano, 1941; Salas, 1945; Doucet, 1993) identifica fuera del «valle de ocloyas» a poblaciones de churumatas,

2 Las dos versiones del siglo XVII son las de Luis Ernot de 1632 y la de Nicolás Henard en 1647 conocida con el nombre de Vicente Carrafa, al que le fuera dedicada.

3 Las referencias a los puntos cardinales se hacen desde las convenciones cartográficas actuales.

4 Para una referencia más amplia acerca de los churumatas en tiempos incaicos y coloniales, ver del Río y Presta (1984), Espinoza Soriano (1986), Doucet (1993), Ferreiro (1994), Presta y del Río (1995). 
chichas, orejones, apatamas y omanatas yapanatas (Salas, 1945: 56) u «omanatas y apanatas» (Sánchez \& Sica, 1990: 475). Asumimos que estos pueblos se ubicaban al norte del «valle de ocloyas». lácona y Raffino (1993: 267) postularon que tanto churumatas como chichas orejones se localizaban al este de las serranías de Santa Victoria. Salvo por esta mención, los demás autores circunscribieron su análisis al «valle de ocloyas» sin incluir el espacio situado al norte del río Iruya. Ciertos fragmentos de la crónica de Lozano (1941) fueron asociados con las poblaciones del Zenta, cuando consideramos que los datos se refieren a territorios más septentrionales. Postulamos la existencia de dos espacios bien diferenciados que plantearían objetivos de dominación diversos.

Según Lozano (1941: 78), los churumatas y los chichas orejones ocuparon bajo el dominio incaico el mismo espacio en que los señalan los españoles en 1630. Se ubicaban al oriente de las serranías donde explotaban minas de plata en tiempos de los incas. Cuando supieron de la muerte de Atahualpa implementaron estrategias de ocultamiento para evitar que sus asentamientos y minas fueran conocidos. Ocupaban valles de la «cordillera del Perú, en las vertientes hacia el Chaco» en una ubicación inaccesible. Lo que define la precisión de la localización de estas poblaciones es la mención a Santiago de Guadalcázar, fundada por Ledesma de Valderrama a fines de 1625 y abandonada hacia 1632. Esta ciudad se emplazaba en la margen oeste del río Bermejo, entre las desembocaduras de los ríos Zenta y San Francisco (Bidondo, 1978: 311). Basado en las cartas del padre Osorio de 1628, Lozano (1941: 20) plantea que estas poblaciones estaban ubicadas doce leguas al noroeste de Guadalcázar, en la Cordillera Oriental, en una latitud entre Cangrejos y Sococha, poblados localizados en la puna jujeña (fig. 1). La ubicación de estas poblaciones al este de la Cordillera Oriental es reafirmada por Ledesma de Valderrama, quien las ubica a 15 leguas del camino real que comunicaba por la puna el Tucumán con Potosí (Salas, 1945: 66, cita 3).

Según Lozano (1941:78-79) los churumatas y los chichas orejones habitan en once pueblos: Yiraque, Chebe, Porame, Topo, Lataharpe, Tacsuy, Cordory, Yaurapé, Chuqui, Capra y Yosparahé, ninguno de los cuales se menciona en la cartografía. El jesuita calcula en 6000 la población de estos grupos a los que identifica como «gente del Perú», a quienes los incas dispusieron para la «conquista de la cordillera» y en la explotación de minas de plata.

Los churumatas serían unos 1500; junto con los chichas orejones realizarían tareas minero-metalúrgicas. Se los identifica como poblaciones pastoras de camélidos y agricultoras, que hacían «grandes sementeras» (Lozano, 1941: 61-79). Además, los incas se sirvieron de ellos como militares para resguardar la frontera de las incursiones chiriguanas. Lozano relata que estos grupos bajaban al río Bermejo a pescar destacando su valentía al incursionar en la selva donde habitaban poblaciones chiriguanas.

Posiblemente, los chichas y churumatas hayan disfrutado de una mayor jerarquía que los otros grupos, en una situación semejante a la del enclave incaico de Cochabamba donde la mayor parte de las tierras estatales fueron cultivadas por mitayos de pueblos cercanos y donde los mitmaqkuna permanentes tenían funciones jerarquizadas (Lorandi, 1984: 140). 
Otra mención a las poblaciones de churumatas, chichas y orejones, asociados a minas de plata y ubicados en estos valles orientales al noreste de Humahuaca corresponde al mapa anónimo que Thierry Saignes (1985) registró en la Biblioteca Nacional de Francia (BNF) que dataría de la primera mitad del siglo XVII. Abarca desde Potosí hasta Humahuaca e incluye nuestro espacio de estudio (fig. 2) y, de acuerdo con el análisis de José Luis Balbuena (1996), su información es altamente confiable.

El mapa contiene más de 20 signos cartográficos, cuyas referencias no se explicitan. En el espacio analizado se indica el «río Bermejo», la «quebrada Seca», la «Cuesta de Cuyambuyo» y los ríos «R. Ipeo» (Lipeo) y «R. Bocayy» (¿Bacoya?), presentes en los mapas actuales, ubicados los cuatro primeros al noreste de la zona en estudio, registrando en Coyambuyo asentamientos chiriguanos en documentación posterior. Este espacio tiene la menor cantidad de signos cartográficos pero presenta dos inscripciones. Suponemos que, en este caso, la falta de indicadores podría remitir al menor conocimiento del área por parte del cartógrafo.

En el sector delimitado por dos serranías, dice (fig. 2):

En el camino de la ciudad de Santiago de Guadalcázar en el Chaco que hay treinta leguas de los Cangrejos una legua antes se juntan los ríos Lupo y Vermejo.

Además, sobre la otra serranía, se lee «A las faldas de esta cordillera que divide el Chaco del Piru estan los churumatas chichas y orejones hay minas de plata». Por último, se señala a «los chipanas», representados con unos círculos concéntricos, signos cartográficos que podrían señalar poblaciones indígenas no reducidas.

La descripción del mapa evidencia la riqueza para el análisis de la territorialidad del Chaco. Por un lado, se destaca la ubicación de las poblaciones de churumatas, chichas y orejones en relación a asentamientos establecidos (Los Cangrejos, en la Puna jujeña) y a puntos geográficos (confluencia de los ríos Lupo y Bermejo y la Cordillera Oriental), señalando además, la presencia de minas de plata. Es interesante la mención de «los chipanas», debido a que esta palabra refiere, tanto en quechua como en aymara, a una «axorca o manilla de los hombres» o «manilla de oro, plata o cobre». Una manilla es una pulsera o brazalete que usaban los hombres. Ya se ha propuesto que la mención de «los chipanas» pudo haber nombrado a una población caracterizada por realizar tareas de orfebrería conocida por la fabricación de pulseras, brazaletes, brazales, coronas y otros objetos de metal. También nos hemos preguntado si esta denominación podría asociarse a «los plateros» que menciona Lozano (Ventura \& Scambato, 2013). Lozano (1941: 78-79) refiere al uso de chipanas por parte de los churumatas y chichas orejones quienes, además de explotar las minas de plata, utilizaban ese metal para fabricar su ajuar «y hacen adornos para sus mujeres, y los hombres chipanas, penachos y pillos [coronas] para bailar al uso del Inga». Resulta significativa la referencia a estas poblaciones de agricultores y pastores que trabajaban en minas de plata y elaboraban objetos de metal como brazaletes y coronas y que aún mantenían algunas costumbres como ciertas festividades a la usanza incaica. 


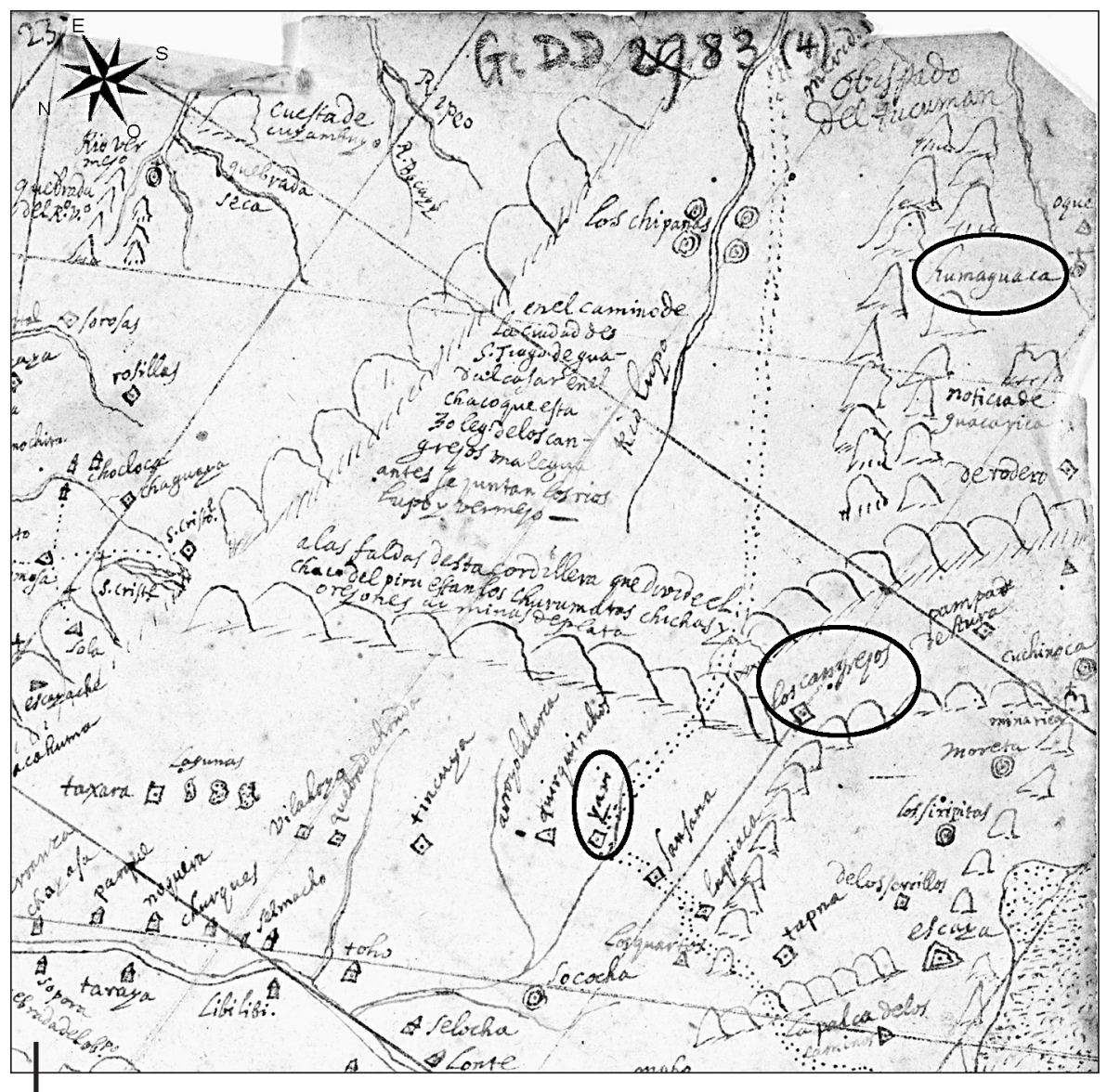

Figura 2 - Mapa de la Biblioteca Nacional de París (fragmento)

Los resaltados son agregados nuestros

Anónimo (primera mitad siglo XVII)

Para Espinosa Soriano (1986), los chichas orejones que menciona Lozano eran una colonia de mitmaqkuna chichas colocados por los incas para defensa de esa frontera y para explotar las minas de oro y plata allí existentes que, debido a la peligrosa función que cumplían, fueron compensados con el rango honorífico de «incas por privilegio».

Sin embargo, sobre los orejones que vivían junto a los churumatas, una relectura de las citas de Lozano (1941: 79) a las cartas del Padre Osorio de 1628, nos permite identificar dos grupos. Por un lado, los que eran mitmaqkuna puestos por los incas para explotar las minas de plata y para la conquista de las serranías, a los que menciona como chichas orejones. Por otro lado, había otras poblaciones de «orejones» provenientes del Cusco, cuya función era «recoger los tributos en oro y plata para el Inga»(Lozano, 1941: 20). Estos grupos, al enterarse de la caída del poder central, «no quisieron volver al Perú, y se quedaron en tierras de 
los Churumatas» (Lozano, 1941: 78-79,18), ocultándose en esos valles de difícil acceso a fin de evitar la dominación española. Probablemente, el autor utilizó como fuente la carta de Ledesma de Valderrama quien en 1644 escribía que en dos valles ubicados en la Cordillera de los Chichas había 3000 indios «de los ingas orejones del Cuzco y churumatas, que se retiraron a ellos cuando los españoles entraron en el Perú y prendieron al Inca en Cajamarca». Estas poblaciones cumplirían tareas minero metalúrgicas en esa cordillera (Salas, 1945: 66, cita 3).

En otra carta, Ledesma de Valderrama afirma, en relación a los orejones que

La segunda nación es de indios ingas del Cuzco, capitanes del Inga, que la tenía en el valle donde está poblada la ciudad de Jujuy, al tiempo que Francisco Pizarro o sus capitanes entraron en el Cuzco; y con la nueva de su venida y muerte del Inga desampararon el valle, y por cima de la cordillera de los indios ocloyas, yéndola costeando, /fueron/ hasta un valle donde hoy están, que también están /sic/ sobre el nacimiento del sol y se escondieron en el (Doucet, 1993: 45).

Es decir que este grupo de orejones, asentados en el valle de Jujuy, al saber de la derrota del Inca, abandonaron ese valle, subieron las serranías («cordillera de los indios ocloyas»), la bordearon Ilegando a otro valle, donde se escondieron. Estos orejones, ibuscaron el mismo espacio en el que estaban ocultos los orejones que iban a recoger el tributo del Inca? Por otro lado, la expresión «que también están» ¿refiere a otro grupo de orejones ubicados en los llanos orientales o a que el valle en el que se asentaron se encontraba al este de la cordillera de los indios ocloyas? En el primero de los casos, ¿podría un grupo de orejones haber buscado un espacio más alejado hacia el oriente y refugiarse en la selva o en el monte chaqueño?

En la cartografía consultada del siglo XVII figuran los «Orejones» u «Orechones». En los mapas jesuitas $(1609,1631$ y 1647) los «orechones» se hallan ubicados en el oeste del «Chaco»y al oriente de unas serranías y de un río sin nombre, localizados al noreste de los «occloias» e identificados con el signo cartográfico de «infieles en territorios desconocidos». En el mapa anónimo (BNF) se los menciona como «orejones» ubicándolos al este de la «Cordillera que divide el Chaco del Peru», junto a los churumatas y chichas, al noreste de Humahuaca. Se los refiere como «chichas y orejones» separando ambos grupos. En el mapa de 1683 (AGI, 1683) los «orejones» figuran al noreste de Jujuy, sobre un río sin nombre que desemboca en el Bermejo, en el «Chaco». En los mapas jesuitas, «chichas» identifica a un gran espacio ubicado al oeste del área analizada, Ilegando hasta el noroeste de Omaguaca, mientras que en el mapa de 1683 no son mencionados. Fuera del «valle y provincia de ocloya» se identifica a las poblaciones que habitaban Titiconde, a los apatamas (que no deben confundirse con los puneños atacama5, omanatas yapanatas (Salas, 1945: 57) u omanatas y apanatas (Sánchez \& Sica, 1990). Excepto para los dos primeros, no contamos con más información que la mención a una merced entregada en 1601 a Juan Ochoa de Zárate citada por

5 Para mayores referencias sobre los apatamas, ver Presta (en prensa). 
Salas (1945) quien los presenta como habitantes del oriente de Humahuaca pero fuera del «valle de ocloyas», aunque sin una ubicación precisa.

Conocemos tres menciones documentales entre 1540 y 1601 al «poblado y valle de Titiconde», y vale la pena considerarlas pues al ser tempranas podrían proporcionar información sobre tiempos incaicos. Las primeras corresponden a las encomiendas que recibieron Martín de Tortoles y Juan de Villanueva en 1540, mostrando la importancia que el sitio tuvo para el Inca. Es probable que Pizarro haya obtenido información sobre Titiconde a partir de los quipus conservados por la administración incaica en el Cusco. Tortoles no pudo disponer de la mano de obra de las poblaciones de Titiconde pues la zona se encontraba fuera del dominio colonial (Presta, 2000: 257). Villanueva recibió una encomienda de omaguacas que incluía grupos sujetos a su curaca y que habitaban Titiconde (el cual se anota como Quiticonde) junto a su principal Jambon (Oliveto, 2011: 143). La siguiente mención está en el testimonio de la encomienda otorgada en 1601 a Juan Ochoa de Zárate, quien recibió el pueblo de Titoconde con el cacique don Francisco Socoar, sucesor del cacique Socomba (Salas, 1945: 56). Sánchez \& Sica (1990) difieren en cuanto al nombre del poblado y del cacique a quienes consignan respectivamente como Titiconte y Francisco Chocoar6.

La referencia documental a Titiconde fue asociada por Salas (1945) con el poblado arqueológico del mismo nombre, considerando que era habitado por poblaciones distintas a los de la «provincia de ocloyas», aunque se encontraba en sus inmediaciones.

Es, entonces, en este sector de los valles orientales de las serranías de Santa Victoria, al norte del río Iruya donde aparecen menciones más detalladas respecto de la producción minera, tareas metalúrgicas y a poblaciones con estatus diferenciados que podrían asociarse a la reestructuración que los incas realizaron en estos valles. Sintetizando, los incas parecen haber organizado dos espacios productivos diferenciados. En el primero y más septentrional se destaca la producción minero-metalúrgica y agrícola con la ocupación de churumatas, chichas y grupos jerarquizados, los orejones. Además, hay presencia de otros («los de Titiconde») no identificados étnicamente pero aparentemente diferentes al resto de los grupos de la zona. Al sur del río Iruya, se registra también producción agrícola sobre la base del trabajo de ocloyas, paypayas, osas, churumatas, gaypetes, chuis. La ausencia de menciones en fuentes y cartografía del siglo XVII a ciertos grupos como los chuis hace suponer que el colapso del dominio incaico debido a la invasión ibérica, provocó su retorno a los lugares que habitaban previamente al traslado inca. La permanencia de las menciones en documentos y mapas permite colegir el derrotero de otros colectivos como churumatas, ocloyas y orejones. En el caso de ciertos grupos de churumatas y orejones, sus migraciones son intentos de escapar del dominio español, lo cual lograron hasta por lo menos mediados del siglo XVII. En el caso de los ocloyas, paypayas, gaypetes, osas y otros churumatas

6 Palomeque (2006) menciona a Lorenzo Chocoar como aspirante al cacicazgo de Casabindo en 1661. 
puede seguirse su paulatino sometimiento al régimen colonial a partir de su reparto en encomiendas y traslado hacia valles más cercanos a la ciudad de Jujuy. Finalmente, es de suponer que la desarticulación de la ocupación incaica desde el siglo XVI haya permitido el ingreso a estos valles de incursiones chiriguanas y mataguayas desde el oriente, acelerando los procesos descriptos.

\section{LA PRESENCIA INCAICA SEGÚN EL REGISTRO ARQUEOLÓGICO}

La huella de la presencia incaica en estos valles orientales ha quedado plasmada en la excelente andenería agrícola que se extiende en las laderas de los cerros, en los santuarios en las cimas de algunas montañas, en las piezas dejadas en los ajuares funerarios, u ocultas dentro de oquedades, o en la arquitectura de algunos asentamientos. Han sido diversos los contextos de hallazgo de estos materiales en los distintos valles de la región que indican algunas de las transformaciones que impuso el Tawantisnsuyu en su frontera oriental.

El estudio del registro arqueológico regional nos ha permitido distinguir ciertas diferencias así como notar las similitudes que presentan los sitios que se distribuyen en dos sectores de la región ubicados al norte y sur del valle del río Iruya.

En la región detectamos una treintena de asentamientos dispersos, que podrían considerarse sitios residenciales o poblados, conformados por unos diez a treinta recintos circulares simples (Ventura, 1999). Algunos se localizan en los sectores altos y laderas medias de los cerros, registrándose, en varios casos, surgentes de agua que abastecían al sitio, mientras que otros sitios residenciales se ubican en los sectores más bajos, en la cercanía de confluencia de ríos.

Estos asentamientos, con recintos circulares presentan áreas de circulación definidas y muros de contención separando los niveles aterrazados de los sitios. Hay también asentamientos de menor tamaño, conformados por 5 a 10 recintos circulares, dispersos en antiguos campos de cultivo. En todos los casos, se registran en sus cercanías, áreas agrícolas y numeroso material lítico de molienda.

Al sur del río Iruya, en los valles de Zenta, Querusillal y San Andrés la mayor parte de los asentamientos se ubican en el ambiente de bosque montano (2000 msnm). Sus tamaños varían entre diez y treinta recintos circulares, de muros simples que no muestran construcciones muy esmeradas. En este ambiente de bosques y praderas con amplias planicies no se registra andenería agrícola, sino numerosos túmulos de despedre que indican la presencia de antiguos campos de cultivo (Ventura, 1999).

La cerámica que proviene de los asentamientos del valle de Zenta-San Andrés, presenta decoraciones incisas y con aplicaciones por pastillaje e incisos, características atribuidas a poblaciones orientales. Además, se registra material cerámico proveniente de la quebrada de Humahuaca e incaico. Estos últimos corresponden a piezas muy móviles (platos patos, vasijas pequeñas, maza estrellada y hacha en $\mathrm{T}$ líticas), ubicadas, en un par de casos, en oquedades o lugares poco visibles que podrían corresponder a ofrendas (Ventura 1999; 2007). 
En estos asentamientos aún no se ha registrado metalurgia ni otros elementos considerados de prestigio.

Al norte del río Iruya, los asentamientos se localizan en el ambiente de Pastizales de neblina (cerca de los 3000 msnm). La arquitectura en este sector se caracteriza por presentar recintos circulares-elípticos de paredes dobles. En ciertos casos, sus construcciones son muy esmeradas con recintos que presentan piedra canteada y aberturas con vanos trapezoidales y rectangulares. Los muros se han construido con piedras seleccionadas (bloques rectangulares), algunos de ellos exhiben nichos y techos con técnica de falsa bóveda. Solo en unos pocos asentamientos se registra una estructura rectangular.

En estos valles hay extensas superficies con andenería agrícola (fig. 4), mostrando concentración en ciertos sectores de andenes y estructuras de almacenamiento de muy buena construcción. Estas estructuras, que pueden presentarse dispersas en los espacios de cultivo, son también circulares, aunque de menor tamaño, tienen techos en falsa bóveda y en, algunos casos, los recintos están intercomunicados.

Hay numeroso material lítico asociado a tareas agrícolas, destacándose gran cantidad de palas. A algunas de ellas, halladas en los entierros, de gran tamaño y formas distintivas con aletas laterales, se les ha atribuido valor simbólico (Márquez Miranda, 1939) (fig. 4).

En los asentamientos se registra mayor cantidad de cerámica «Yavi-Chicha» e Inca (fig. 3), principalmente en los ajuares funerarios, y muy poca cerámica incisa y, hasta el momento, ninguna que pudiera asociarse a las poblaciones de bosques y selva.

En este sector, al norte del valle de Iruya, dos asentamientos se diferencian del resto, por su tamaño, arquitectura y materiales: Titiconte, ya mencionado, y Pueblo Viejo de Rodeo Colorado (fig. 1), con 50 y unos 100 recintos, respectivamente.

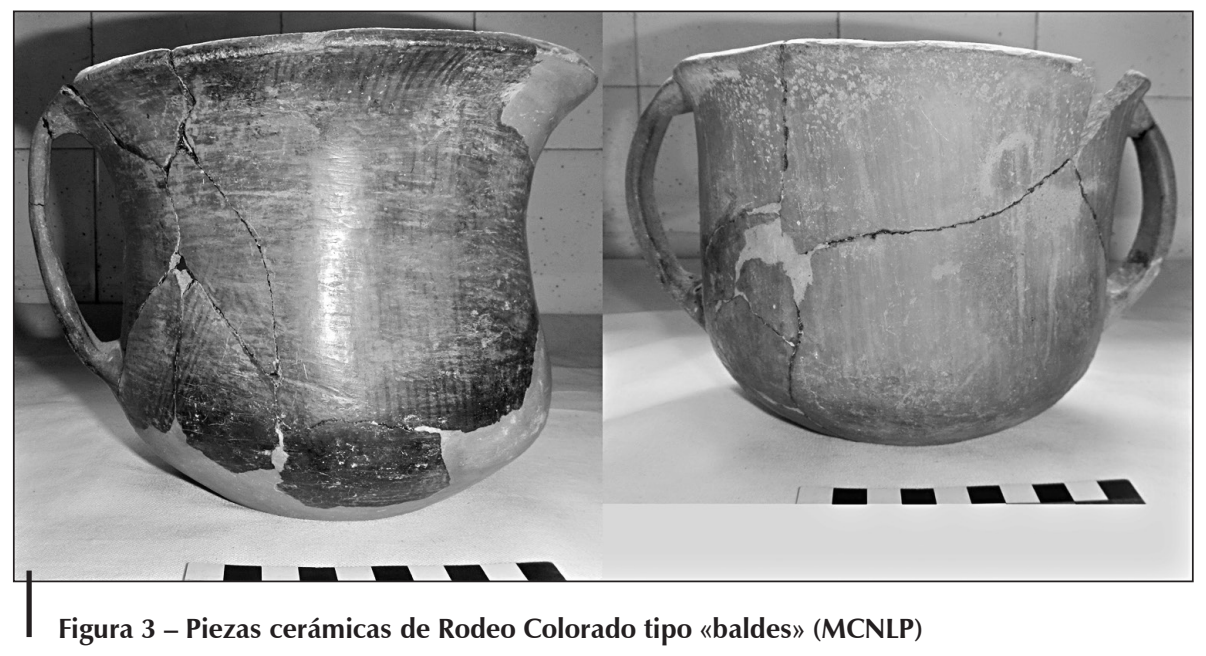




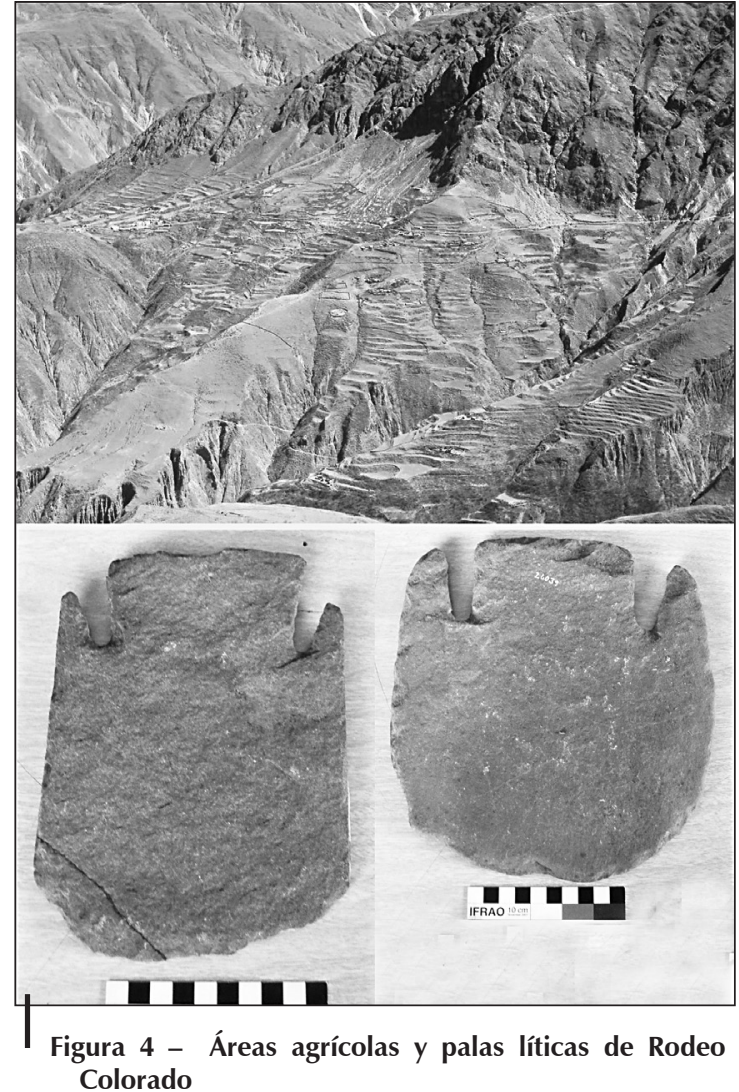

MCNLP
Titiconte $\left(22^{\circ} 47^{\prime}\right.$ lat. sur y $65^{\circ} 10^{\prime}$ long. oeste) se ubica en la cima de un cerro dominando el valle de Iruya (fig. 1) y fue excavado por Debenedetti \& Casanova (1933-1935) y por Márquez Miranda (1939). Este asentamiento se caracteriza por su inusual arquitectura con recintos residenciales y de almacenamiento rectangulares y circulares, de muy buena construcción con piedras lajas seleccionadas. Algunas de estas estructuras circulares son semisubterráneas, con aberturas de vanos trapezoidales, techos en falsa bóveda y pisos empedrados con lajas y, en ciertos casos, se hallan intercomunicadas por túneles o corredores que llegan a medir $12 \mathrm{~m}$ de largo. También, contaba con una surgente de agua que abastecía al poblado, el cual se halla rodeado en su lado norte de una muralla. Se destacan los sectores agrícolas con notable andenería y estructuras de almacenamiento (Debenedetti \& Casanova, 1933-1935; Márquez Miranda, 1939). Raffino et al. (1986) consideran que este sitio era un centro administrativo incaico del cual parte un tramo del qhapagñan en dirección sur uniendo otros centros agrícolas. En el sitio registran en superficie, alfarería humahuaca, chicha e inca. Posteriormente Raffino et al. (2006) lo mencionan como una instalación Inca-Chicha.

Un dato a resaltar en Titiconte es la representación de llamas blancas realizadas con técnica de mosaico en las paredes de los andenes de cultivo (Debenedetti \& Casanova, 1933-1935; Márquez Miranda, 1937), rasgo hasta ahora no registrado en otros sitios incaicos del NOA pero que recuerda a las llamas blancas representadas en los andenes del sitio incaico Choquequirao, en el Perú (Echevarría López \& Valencia García, 2011; Ventura, 2013).

Titiconte, a pesar de su notable construcción, que difiere de otros asentamientos incaicos del NOA, presenta escasos materiales considerados de prestigio. En las excavaciones se registraron pocas piezas de metal, entre ellas, un par de fragmentos de objetos de plata y una pieza antropomorfa de bronce que fue asociada a otras halladas en el Titicaca, en Bolivia (Debenedetti \& Casanova, 1933-1935). El hallazgo de abundante material lítico de molienda y de recintos de almacenaje relaciona este sitio con tareas agrícolas y de almacenamiento, mientras que su emplazamiento permitiría el control del valle de Iruya, vía de comunicación directa con los bosques y selvas (Ventura, 2013). 
El otro asentamiento de mayores dimensiones, Pueblo Viejo de Rodeo Colorado

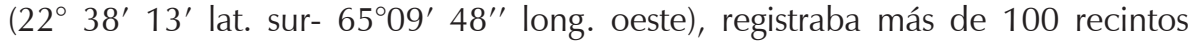
cuando Márquez Miranda (1939) lo excavó entre los años 1933 y 1938. Este sitio se ubica en el sector medio de la ladera de un cerro, en las cercanías del valle de Nazareno (fig. 1) y cuenta casi exclusivamente con recintos circulares simples, ya que presentaba una estructura rectangular. Los recintos residenciales circulares se distribuyen en 10 niveles aterrazados, con muros de contención que delimitan áreas de circulación, mientras que dos surgentes abastecen de agua al sitio. Proveniente principalmente de los entierros, ubicados dentro de los recintos residenciales, se hallaron diversos elementos considerados de prestigio tales como una compleja metalurgia, cuentas de collares de turquesas, sodalita, conchillas, etc. (fig. 5). Así como restos de textiles de buena calidad, instrumentos musicales, representaciones antro y zoomorfas en piedra, vasos cerámicos (tipo «baldes») asociados a alfarería puneña y cerámica inca (fig. 3). Se registraron en el sitio 36 piezas de metal, correspondiendo a pulseras, brazaletes (chipanas), brazales, manoplas, anillos, aro, placas circulares y rectangulares, campanas, etc. (fig. 5), cuyos análisis determinaron plata, bronces y cobre. Se halló también una bola de plomo (Ventura \& Scambato, 2013). Destacamos la presencia de instrumentos musicales de piedra, de gran importancia en las celebraciones rituales. Estos elementos de prestigio estarían dando cuenta de una población diferenciada.

Otros asentamientos cercanos presentan características destacadas, como por ejemplo, Huayra Huasi (fig. 1) con recintos circulares en cuya construcción se utilizaron piedras canteadas, en donde se hallaron piezas de oro (4 «campanillas» o cubiletes) y otros elementos alóctonos de prestigio, entre ellos una placa de bronce decorada (placa rectangular santamariana) (Márquez Miranda, 1939; Ventura y Scambato, 2013).

Destacamos también en estos sitios el registro de piezas de metal que presentan similitudes con otras halladas en Machu Picchu, Perú, como una pulsera de plata de Cuesta Azul decorada con incisiones dentro de triángulos y placas circulares de plata de distintos tamaños halladas en Pueblo Viejo de Rodeo Colorado y Molino Viejo (Burger \& Salazar, 2004; Ventura \& Scambato, 2013), que plantearían interacciones a larga distancia.

Es significativo que todos estos materiales se registraran al norte del río Iruya, espacio en el que la documentación indica que se encontraban, en tiempos incaicos, los mitmaqkuna que cumplían funciones ligadas a la minería y metalurgia. El cumplimiento de estas tareas contribuiría al estatus privilegiado de ciertos grupos. Según la documentación, un reducido número indicado como «orejones del Cuzco», eran enviados desde allí, o desde algún otro centro de poder, para cumplir tareas de control y recolección de lo producido, moviéndose entre diversos centros mineros-metalúrgicos. Al conocer la noticia de la caída del Inca, se establecieron definitivamente en estos valles. Los indicadores materiales asociados a este tipo de grupo jerarquizado podrían corresponder a asentamientos con rasgos arquitectónicos destacados (piedra canteada en las viviendas, elaborada andenería). También, a piezas de alto valor simbólico tanto por el material en 


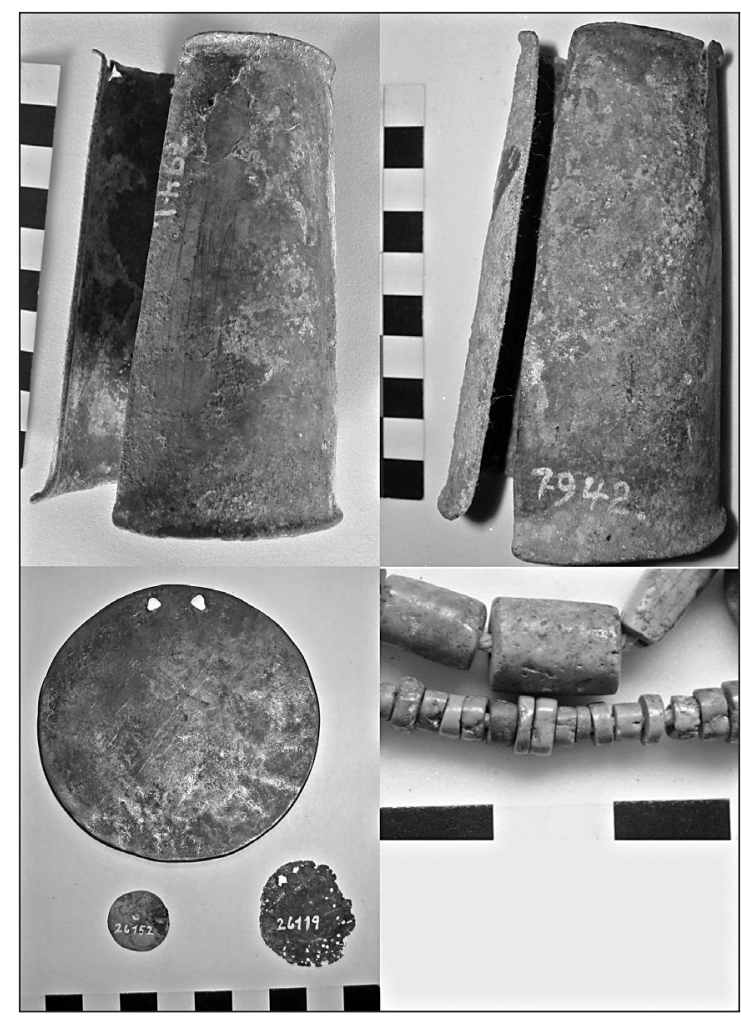

Figura 5 - Brazaletes de bronce y placas circulares de plata. Collar de cuentas de turquesa

Rodeo Colorado (MCNLP) que están confeccionadas (oro) como por tratarse de objetos suntuarios de restringida circulación por provenir directamente del Inca como pares de «campanillas» o «cubiletes». Estos materiales se asocian con otros bienes alóctonos, piezas pequeñas y de fácil traslado como cuentas de turquesa y sodalita, también a otros objetos portadores de una iconografía de gran estima para algunas de las poblaciones dominadas que evidencia el conocimiento y valoración de una ideología compartida. Sería el caso de la placa rectangular santamariana, cuya dispersión llega hasta Sacsahuaman, en el Perú, indicando intercambio y contacto a lo largo de rutas que unían otros centros bajo dominio inca.

La serranía de Santa Victoria presenta variedad de yacimientos metalíferos. Las manifestaciones de plomo-plata-zinc son frecuentes, así como de cobre, hierro y oro. En el norte se presentan también placeres auríferos. Es decir que la base geológica de la zona sustenta la posibilidad de la explotación minero metalúrgica que manifiestan las fuentes y el registro arqueológico (Ventura \& Scambato, 2013).

Se identificaron una serie de cerros mineros (como Cerro Fundición y Cerro Minero), ubicados en las cercanías de estos asentamientos y en relación a ciertos sectores agrícolas, lo cual podría responder a la planificación de la ocupación incaica que buscaba articular espacios productivos (Ventura, 2013).

Otro tipo de sitios se emplazan en la cima de cerros altos como el santuario de altura de Cerro Morado (Casanova, 1930), ubicado al norte, en el nacimiento del río Iruya, y, al sur, el Cerro Incahuasi, en el valle de Zenta-San Andrés (Ventura, 1999; 2011) (fig. 1). Estos santuarios evidenciarían formas complementarias de dominación sobre las poblaciones allí relocalizadas y en relación a áreas mineras, en el caso de Cerro Morado.

Algunos asentamientos en el valle de Zenta-San Andrés fueron interpretados, a partir de información documental, como parte de enclaves defensivos incaicos. Sin embargo, creemos que podrían haber sido sitios de observación y control del valle, de ubicación estratégica en la comunicación con la selva. La misma función la atribuimos a otros sitios en los valles de Nazareno y Bacoya (Ventura, 2013) 


\section{CONCLUSIONES}

Los valles orientales del norte de Salta, ubicados en las Yungas argentinas, formaron parte de «el Chaco» colonial que abarcaba las serranías, los bosques y selvas aledañas. Así, la idea del territorio chaqueño asociado actualmente a la Ilanura chaqueña no corresponde con la definición de los siglos XVII y XVIII que inclúa una diversidad mayor de ambientes, que no debe soslayarse en el estudio de la documentación para interpretarla de manera apropiada.

Estos valles formaron parte de la frontera oriental del Tawantinsuyu en cuya configuración cumplió un rol central el traslado de poblaciones de orígenes diversos como mitmaqkuna. Este espacio fronterizo presenta una gran diversidad de asentamientos arqueológicos dispersos, de reducido tamaño y de corta duración que corresponden con la imagen que las fuentes documentales trasmiten.

El análisis de las fuentes históricas y arqueológicas fundamenta la propuesta acerca de la estructuración incaica de dos espacios diferenciados en estos valles orientales, que podríamos ubicar, aproximadamente, al norte y sur del río Iruya, que estaría en relación con los diversos objetivos llevados a cabo en este territorio de frontera.

En el espacio ubicado al sur del valle de Iruya los objetivos del Tawantinsuyu parecen, hasta el momento, relacionarse con la explotación agrícola en el sector de los bosques montanos en donde se distribuyen pequeños asentamientos tanto en la cima de cerros bajos como en inmediaciones de confluencias de ríos y, probablemente, también se relacionaran con el uso y explotación de recursos del bosque y las selvas cercanas. El valle de Zenta-San Andrés fue, además, un área de comunicación entre las selvas y la quebrada de Humahuaca y la instalación allí pudo haber estado relacionada con el control de esta vía de circulación. En este sector, las evidencias arqueológicas se relacionan con actividades de subsistencia, siendo mínima la presencia de bienes suntuarios. A pesar de la clásica referencia a los ocloyas de Sotelo de Narváez de 1582 como habitando una «tierra de mucho oro», hasta el momento, no se han registrado objetos de metal en estos valles. Los ocloyas, churumatas, osas, chuis, gaypetes y paypayas son las poblaciones relocalizadas identificadas en el «valle de ocloyas». En este espacio los incas posiblemente transformaron las relaciones políticas entre las poblaciones de los valles orientales y las de la quebrada de Humahuaca al subordinar a los ocloyas a los omaguaca.

Al oriente de las serranías de Santa Victoria, en el sector más septentrional, en el límite con lo que actualmente es Tarija en Bolivia, los objetivos incaicos fueron principalmente minero-metalúrgicos en las minas de cobre, plata y oro de la zona, datos que la geología sostiene. Para la explotación de esos recursos se trasladó a ciertas poblaciones, posiblemente especialistas en esas tareas, que contaron con estatus privilegiado y se realizó una gran inversión en infraestructura agrícola, tanto en andenería de muy buena construcción como en recintos de almacenamiento. Uno de los principales asentamientos residenciales es Pueblo Viejo de Rodeo Colorado, sitio asentado en un espacio de gran concentración 
de andenería agrícola y ubicado en cercanías del Cerro Minero. Este esquema se repite más al norte cerca del Cerro Fundición.

El control político sobre estos valles se manifiesta en la localización sobre el río Iruya de un centro administrativo, Titiconte, relacionado principalmente con los recursos agrícolas y, posiblemente, el control de la circulación de esa vía de comunicación con los bosques y selvas. La instalación de un santuario de altura en Cerro Morado, refiere a un tipo de apropiación simbólica del paisaje de estos valles orientales, en relación con un área minera y otra forma de dominación sobre las poblaciones relocalizadas.

A los grupos que ocupaban los valles de Iruya, Nazareno y Bacoya las fuentes y la evidencia arqueológica los asocia a actividades minero-metalúrgicas, agrícolas y ganaderas. Se mencionan en la documentación a churumatas, chichas y orejones sosteniendo este enclave productivo; sin embargo, no podemos aún establecer una referencia étnica directa entre esas menciones y el registro arqueológico. Las escasas referencias a otras poblaciones como apatamas, omanatas y apanatas y «los de Titiconde» no permiten conocer las funciones que cumplieron bajo el dominio incaico. Sin embargo, en relación a los últimos, las tempranas menciones documentales pueden asociarse al sitio arqueológico Titiconte de funciones administrativas y productivas.

En este sector los incas también habrían reestructurado los vínculos políticos preexistentes subordinando unos grupos a otros y elevando, a partir del nombramiento de orejones, ciertos sectores poblacionales sobre los demás, tal sería el caso de los chichas. Debido a las características del enclave, los incas parecen haber establecido, además, un control más directo a partir del envío de representantes del Cusco para «recoger los tributos para el inga» (Lozano, 1941: 18).

Las fuentes nos permiten delinear algunas características de los significativos movimientos poblacionales que se produjeron cuando llegó al Chaco la noticia de la muerte de Atahualpa. Suponemos que esto inició la desarticulación de los enclaves productivos incaicos que se profundizó por la presión de los grupos chiriguanos y mataguayos que avanzaron sobre estos valles orientales. Otros movimientos quedaron registrados como estrategias de ocultamiento para churumatas y chichas y de refugio para diversos grupos de orejones, que se escondieron en estos valles orientales con el expreso objetivo de permanecer fuera del dominio colonial castellano, habida cuenta del conocimiento que tenían del accionar de los españoles, especialmente en relación con las áreas mineras (Lozano, 1941: 20).

En la cartografía consultada del siglo XVII se registra, en todos los casos, la mención de los orejones en el Chaco, en áreas no conquistadas y al noreste de los ocloyas. A estos se los identifica en los mapas jesuitas como grupo localizado al este de Humahuaca, distribuidos en algunas poblaciones de ubicación posiblemente prehispánica. En cuanto a los churumatas, solo aparecen mencionados en el mapa anónimo (BNF) vinculados a chichas y orejones, localizados al este de la Cordillera Oriental y fuera del dominio colonial, en serranías con minas de plata. En esta carta se registra a «los chipanas» como poblaciones no conquistadas que asociamos a 
grupos relacionados con tareas metalúrgicas y de orfebrería. El espacio chicha se señala en la cartografía jesuítica. Las demás poblaciones no se mencionan en la cartografía salvo por los chiriguanos, mataguayos, tobas y frentones que se ubican al este de estos valles orientales y su análisis excede los límites de este trabajo.

El diálogo entre las referencias documentales, el registro arqueológico y los mapas procedentes de diferentes fuentes productoras, nos permiten señalar que los aportes de Lozano merecen ser tomados en cuenta para la localización de las poblaciones de churumatas, chichas y orejones, tanto para tiempos incaicos como coloniales.

Las fuentes etnohistóricas, la cartografía y la arqueología nos han permitido profundizar el análisis de las trasformaciones en la territorialidad operadas en este sector de la frontera oriental del Tawantinsuyu que se manifiesta como un espacio de movilidad y multietnicidad. Esperamos que las propuestas y reflexiones de este trabajo estimulen futuras investigaciones que amplíen el conocimiento sobre la integración de este sector del Qollasuyu dentro de las variantes que presentaron las políticas de administración y control inca en su extenso dominio suroriental.

\section{Agradecimientos}

Agradecemos a Thibault Saintenoy y al revisor anónimo quienes mejoraron nuestro trabajo con sus comentarios, al igual que Silvia Palomeque. A Juan Pablo Ferreiro por habernos facilitado documentación del ATJ; a Federico Garcia Blaya, Olga y Jim Brennan, Roxana Nakasima y Rosana Albertal. Al Museo de Ciencias Naturales de la Plata y a las comunidades de Abra del Sauce y Rodeo Colorado (Iruya) Salta. Esta investigación pudo realizarse con el aporte de subsidios de Conicet (PIP 0327 y PIP 0285).

\section{Referencias citadas}

ARCHIVO DE TRIBUNALES DE JUJUY (ATJ), 1596 - Interrogatorio presentado por Juan Ochoa de Zárate en el pleito por su encomienda de omaguacas. Caja 1, carpeta 4. f. 1-11v.

ALCONINI, S., 2004 - The Southeastern Inka frontier against the Chiriguanos: structure and dynamics of the inka imperial borderlands. Latin American Antiquity, 15 (4): 389-418.

BALBUENA, J. L., 1996 - Yoscava (Yoscaba) en el mapa del Alto Perú, provincia de Potosí, siglo XVII de la Biblioteca Nacional de Paris. In: XXV Aniversario del Museo Arqueológico «Dr. Eduardo Casanova»: 33-46; Tilcara: Inst. Interdisciplinario de Tilcara, FFyL. UBA.

BIDONDO, E., 1978 - Jujuy y el Gran Chaco Gualamba. Santiago de Guadalcázar. Boletin de la Academia Nacional de Historia, 51: 303-319.

BURGER, R. \& SALAZAR, L. (eds.), 2004 - Machu Picchu. Unveiling the Mystery of the Incas, viii +230 pp.; New Haven: Yale University Press.

CABRERA, A., 1976 - Regiones Fitogeográficas Argentinas. In: Enciclopedia Argentina de agricultura y jardinería, tomo II, 85 pp.; Buenos Aires: Acme. 
CASANOVA, E., 1930 - Excursión arqueológica al Cerro Morado. Notas del Museo Etnográfico, 3: 5-40; Buenos Aires.

DEBENEDETTI, S. \& CASANOVA, E., 1933-1935 - Titiconte. In: Publicaciones del Museo Etnográfico, A (III): 1-35.

DEL RÍO, M. \& PRESTA, A. M., 1984 - Un estudio etnohistórico en los corregimientos de Tomina y Amparaez: casos de multietnicidad. Runa, XIV: 221-246.

DOUCET, G., 1993 - Acerca de los churumatas, con particular referencia al antiguo Tucumán. Histórica, XVII, 1: 21-91.

ECHAVARRÍA LÓPEZ, G. T. \& VALENCIA GARCÍA, Z., 2011 - Choquequirao, un asentamiento imperial cusqueño del siglo XV en la Amazonía andina. Haucaypata, 2: 32-43; Lima.

ESPINOZA SORIANO, W., 1986 - Los churumatas y los mitmas chichas orejones en los lindes del Collasuyo siglos XV -XX. Revista Histórica, XXV: 243-297.

FERREIRO, J. P., 1994 - El Chaco en los Andes. Churumatas, paypayas, yalas y ocloyas en la etnografía del oriente jujeño. Población y sociedad, 2: 3-23.

GONZÁLEZ, A. R., 1982 - Las «provincias» inca del antiguo Tucumán. Revista del Museo Nacional, 46/3: 17-380.

IÁCONA, L. A. \& RAFFINO, R. A., 1993 - De Titicaca a Omahuaca durante el siglo XVI. In: Inka. Arqueología, historia y urbanismo del altiplano andino (R. Raffino, ed.): 235283; Buenos Aires: Ed. Corregidor.

LORANDI, A. M., 1984 - Pleito de Juan Ochoa de Zárate por la posesión de los indios ocloyas. ¿Un caso de verticalidad étnica o un relicto de archipiélago estatal? Runa, XIV: $123-142$.

LOZANO, P., 1941 [1733] - Descripción corográfica del Gran Chaco Gualamba, xix + 466 pp.; Tucumán: Inst. de Antropología. Reedición con prólogo e índice por R. A. Altieri.

MÁRQUEZ MIRANDA, F., 1937 - Arquitectura aborigen en la provincia de Salta. Relaciones de la Sociedad Argentina de Antropología, 1: 141-176.

MÁRQUEZ MIRANDA, F., 1939 - Cuatro viajes de estudio al más remoto noroeste argentino. Revista del Museo de La Plata (Nueva Serie), 1 (6): 93-243.

MARTíNEZ, J. L., 1995 - Textos y palabras. Cuatro documentos del siglo XVI. In: Espacio, etnías, frontera. Atenuaciones políticas en el sur del Tawantinsuyu. Siglos XV-XVII (A. M. Presta, ed.): 251-284; Sucre: ASUR.

OLIVETO, L. G., 2011 - Ocupación territorial y relaciones interétnicas en los Andes Meridionales. Tarija entre los desafíos prehispánicos y temprano coloniales; Buenos Aires: FFyL. UBA. Tesis de doctorado

OLIVETO, L. G. \& VENTURA, B., 2009 - Dinámicas poblacionales de los valles orientales del sur de Bolivia y norte de Argentina, siglos XV-XVII. Aportes etnohistóricos y arqueológicos. Población y Sociedad, 16: 119-150.

PALOMEQUE, S., 2006 - La historia de los señores étnicos de Casabindo y Cochinoca (1540-1662). Andes, 17: 139-194.

PALOMEQUE, S., 2010 - Los chichas y las visitas toledanas. Las tierras de los chichas de Talina (1573-75). Prohal Monografico:1-75. http://www.filo.uba.ar/contenidos/ investigacion/institutos/ravignani/ prohal/mono.html

PASTELLS, P., 1912 - Historia de la Compañía de Jesús, T. I.; Madrid: Librería de V. Suárez.

PENHOS, M., 2005 - Ver, conocer, dominar. Imágenes de Sudamérica a fines del siglo XVIII, 382 pp.; Buenos Aires: Siglo XXI editores. 
Resabios de otros tiempos. Dominio incaico en los valles orientales del norte de Salta, Argentina

PRESTA, A. M., 2000 - Encomienda, familia y negocios en Charcas colonial. Los encomenderos de La Plata. 1550-1600, 308 pp.; Lima: IEP, BCRP.

PRESTA, A. M., en prensa - Mapas étnicos en asentamientos fragmentados. El territorio chuquisaqueño en el tardío prehispánico y la temprana colonia. In: Las tierras altas del área centro sur andino entre el 1000 y el 1600 (M. E. Albeck, ed.); San Salvador de Jujuy: UNJu, Tanoa II.

PRESTA, A. M. \& DEL RÍO, M., 1995 - Reflexiones sobre los churumatas del sur de Bolivia, siglos XV-XVII. In: Espacio, etnías, frontera. Atenuaciones políticas en el sur del Tawantinsuyu. Siglos XV-XVII (A. M. Presta, ed.): 129-234; Sucre: ASUR.

RAFFINO, R. R. A., OLIVERA, D. \& PALMA, J., 1986 - La instalación inka en la sección andina meridional de Bolivia y extremo boreal de Argentina. In: El Imperio Inka. Actualización y perspectivas por registros arqueológicos y etnohistóricos: 63-131; Córdoba: Comechingonia. Tomo homenaje al 45으 CIAA.

RAFFINO, R., GOBBO, D. \& IÁCONA, A., 2006 - De Potosí y Tarija a la frontera chiriguana. Folia Histórica del Nordeste, 16: 93-129.

RENARD CASEVITZ, F.-M., SAIGNES, T. \& TAYLOR, A., 1988 - Al este de los Andes. Relaciones entre las sociedades amazónicas y andinas entre los siglos XV y XVII, Tomo I, 322 p.; Quito: Ediciones ABYA-YALA, IFEA.

RUSSO DE BORELLI, M. L., 2007 - Iruya. Ecos de antaño, 199 pp.; Salta: Secretaría de Cultura de la Prov. de Salta, Fundación Capacitar del NOA. Col. Ex Libris.

SAIGNES, T., 1985 - Potosí et le sud bolivien selon une ancienne carte. C.M.H.L.B Caravelle, 44: 123-128.

SALAS, A. M., 1945 - El Antigal de Ciénaga Grande (Quebrada de Purmamarca, Provincia de Jujuy); Buenos Aires: Imprenta de la UBA.

SÁNCHEZ, S., 2003 - Un viaje entre la historia y la memoria. Anuario de estudios americanos, LX, 1: 41-76.

SÁNCHEZ, S. \& SICA, G., 1990 - La frontera oriental de Humahuaca y sus relaciones con el Chaco. Bulletin de l'Institut Français d'Études Andines, 19 (2): 469-497.

SICA, G., 2003 - ¿De qué norte hablamos? Las percepciones históricas del espacio y sus consecuencias en la investigación de las sociedades prehispánicas y coloniales del noroeste argentino. Memoria Americana, 11: 51-72.

SOTELO DE NARVÁEZ, P., 1965 [1582] - Relación de la Provincia de Tucumán. In: Relaciones Geográficas de Indias, T. I (M. Jiménez de la Espada, ed.): 143-153; Madrid: Atlas.

TOGO, J., 1973 - Prospección arqueológica en el Departamento Santa Victoria. Actualidad Antropológica, 12; Olavarría: Museo Damaso Arce.

TOMMASINI, G., 1990 [1933] - Los indios ocloyas y sus doctrineros en el siglo XVI; Jujuy: UNJu.

TORRE REVELLO, J., 1943 - Esteco y Concepción del Bermejo, dos ciudades desaparecidas, xxiii +27 pp.; Buenos Aires: Talleres Casa Jacobo Peuser.

TORRES, D. de, 1927 [1609] - Primera carta del Padre Diego de Torres. In: Cartas Anuas 1609-1614 Documentos para la historia argentina XIX; Buenos Aires: Inst. Investigaciones Históricas. FFyL, UBA.

VENTURA, B. N., 1999 - Arqueología de los valles orientales a las Serranías de Zenta y Santa Victoria, Salta. Buenos Aires: FFyL, UBA. Tesis de Doctorado.

VENTURA, B. N., 2001 - Los últimos mil años en la arqueología de las Yungas. In: Historia Argentina Prehispánica, T. I. (E. Berberián \& A. Nielsen, eds.): 447-492; Córdoba: Ed. Brujas. 
VENTURA, B. N., 2007 - El proceso de ocupación humana de la Finca San Andrés. In: Finca San Andrés. Un espacio de cambios ambientales y sociales en el Alto Bermejo (A. Brown, M. García Moritan, B. Ventura, N. Hilgert \& L. Malizia, eds.): 101-127; Pro-Yungas. Tucumán: Ed. del Subtrópico.

VENTURA, B. N., 2011 - La colección Márquez Miranda. Análisis del material arqueológico proveniente de los valles orientales del norte de Salta (Argentina). CD del II Simposio; Salta: Colecciones de Museos e Investigación, Patrimonio, Diversidad cultural e Inclusión social.

VENTURA, B. N., 2013 - Mirando hacia arriba. Las Tierras altas vistas desde las Yungas salteñas (Argentina). In: Las Tierras Altas del Area Centrosur andina, entre el 1000 y el 1600 d.C. (M. E. Albeck, M. Ruíz \& M. B. Cremonte, eds.): 121-157; Jujuy: Ediunju.

VENTURA, B. N. \& SCAMBATO, A. C., 2013 - La metalurgia de los valles orientales del norte de Salta, Argentina. Boletín del Museo Chileno de Arte Precolombino, 18 (1): 85-106; Santiago.

VENTURA, B. N., BELARDI, J. B. \& WEISSEL, M., 1991 - «Trastornado» el Zenta: una prospección arqueológica desde la Puna a la Selva. Shincal, 3, T. 3: 2-6; Catamarca.

\section{MAPAS}

ARCHIVO GENERAL DE INDIAS (AGI), 1683 - Juan Ramón. Carta Geográfica de la Gobernación del Río de la Plata, Tucumán y Paraguay. AGl. MP-Buenos_Aires, 29.

BIBLIOTECA NACIONAL DE FRANCIA (BNF). Anónimo. Colección Klaproth. GE DD 2983 (4).

FURLONG CARDIFF, G., 1936 - Cartografía jesuítica del Río de la Plata; Buenos Aires: Tall. S.A. Casa Jacobo Peuser. Mapa Ernot, Lámina II (1632), Mapa Carrafa, Lámina III (1647). 